SC 43034

\title{
Fluorescence polarisation aud location of fluorescence maxima of C-phycocyanin
}

Ultracentrifuge studies have shown that phycocyanin, a chromoprotein with a molecular weight of about 270000, falls apart into smaller subunits at high and low $\mathrm{pH}$ (Svedberg and ERIKSson ${ }^{1}$, ERIKSson-Quensel ${ }^{2}$ ). Measurements of the polarisation of phycocyanin fluorescence indicated that the degree of polarisation $p$ is low (o.or) in the $\mathrm{pH}$ range at which the chromoprotein is assumed to be intact ( $\mathrm{pH} 4-6$ ), while it is appreciably higher $(0.20)$ in the $\mathrm{pH}$ ranges in which phycocyanin is assumed to be disintegrated into its smallest subunits (GOEDHEER ${ }^{3}$ ). The curves for fluorescence polarisation and for particle size versus $\mathrm{pH}$ are roughly similar in shape. This phenomenon was given the interpretation, that fluorescence in the intact chromoprotein is depolarised by energy transfer from the absorbing pigment chromophore to neighbouring chromophores attached to the same protein carrier; a splitting of this carrier into subunits, with chromophores attached to each of them, decreases the probability of energy transfer, resulting in a decrease in fluorescence polarisation. Calculation showed, that with the measured values of fluorescence yield and particle size, depolarisation in aqueous suspension due to Brownian rotation is expected not to be high, even for the chromoprotein fragments. The value of $p$ of about 0.20 at high and at low $\mathrm{pH}$ suggests that these fragments still contain more than one chromophore.

BRoDY AND BRODY 4 calculated the number of chromophores from carefully prepared phycocyanin by measuring fluorescence lifetimes and fluorescence yield. For phycocyanin they found a value of $I-2$ pigment chromophores per Svedberg unit of protein.

The intact chromoprotein thus contains a number of chromophores which, according to fluorescence depolarisation, interact with each other. Such a mutual pigment interaction may also affect the difference in wavelength between absorption and fluorescence maximum ("Stokes shift"), as well as the shape and location of the absorption spectrum. In this way, the location of the fluorescence maximum may vary as a function of $\mathrm{pH}$.

To investigate these phenomena we measured fluorescence and absorption spectra of extracted phycocyanin in a $\mathrm{pH}$ range from 2 to 9 , and determined the amount of fluorescence polarisation of the same samples. Phycocyanin was obtained by grinding the blue-green alga Synechococcus cedrorum with sand. Cell debris and sand were removed by two successive low-speed centrifugations ( $15 \mathrm{~min}, 6000 \mathrm{rev}$. per min). Chlorophyll-carrying lamellae were removed by high-speed centrifugation (60 $\mathrm{min}, \mathrm{I} 8000 \mathrm{rev} . / \mathrm{min})$ in a cooled centrifuge. Phycocyanin was not further purified, but was immediately transferred into the buffers for measurement. Citrate buffer (o.or M) was used for $\mathrm{pH} 2-7$, borax buffer for $\mathrm{pH}_{7}-9$. To check a possible influence of type of buffer, phosphate buffer was used at $\mathrm{pH}$ values from 5.2 to 7.5. Absorption spectra were recorded in a Beckmann DK2 spectrophotometer. The phycocyanin concentration was such, that the peak absorbancy was 0.9 at $\mathrm{pH}$ 6.o. The same amount of phycocyanin was used at other $\mathrm{pH}$ values. To avoid reabsorption of fluorescence, the samples were diluted eight times for fluorescence measurements. For polarisation measurements, fluorescence was excited with light of the 546 and $578-\mathrm{m} \mu \mathrm{Hg}$ lines, while fluorescence was separated from scattered incident light by means of a Schott 
$\mathrm{RG}_{5}$ filter (transmitting light of a wavelength longer than $650 \mathrm{~m} \mu$ ). A polaroid filter type HR was used in the fluorescence beam, whereas a normal type polaroid filter was placed in the beam of exciting light.

In Fig. I absorption and fluorescence spectra, measured at $\mathrm{pH} \mathrm{2.2,6}$ and 9 , are given. It is seen that the phycocyanin absorption band was broadened at high and low $\mathrm{pH}$, while the peak absorbancy was markedly decreased. At all $\mathrm{pH}$ values except 2.2, the location of the absorption maximum did not differ by more than $\mathrm{I}-2 \mathrm{~m} \mu$ from the value at $\mathrm{pH}$ 6. At $\mathrm{pH} 2.2$ the absorption maxinum was shifted from $6 \mathrm{I} 7$ to $622 \mathrm{~m} \mu$. The fluorescence spectra remained approximately mirror-symmetrical to

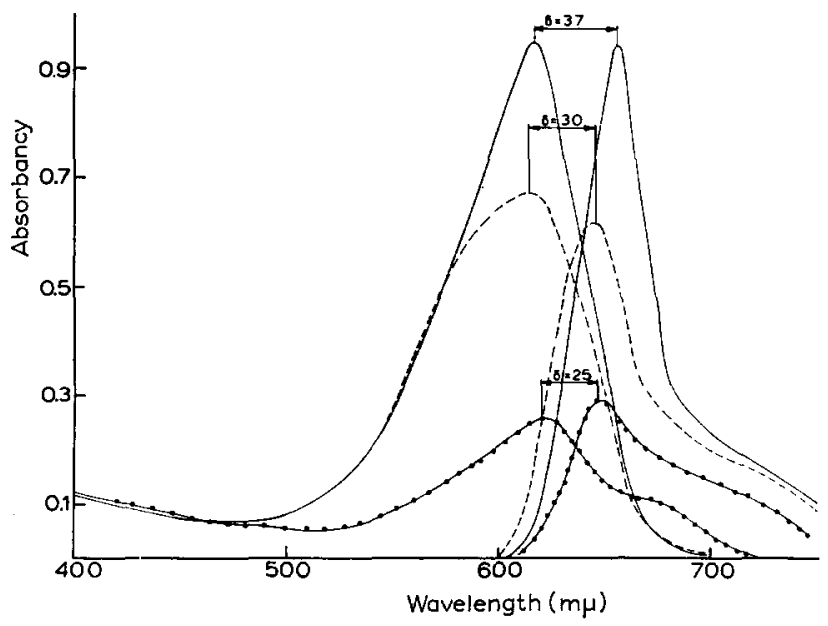

Fig. I. Fluorescence and absorption spectra of C-phycocyanin extracted from Synechococcus cedrorum. Spectra are given of samples buffered at $\mathrm{pH} 6(-), \mathrm{pH} 9(---)$ and $\mathrm{pH} 2.2$ $(-\cdots,-)$, and were measured immediately after preparation.

\section{TABLE I}

LOCATION OF FLUORESCENCE AND ABSORPTION MAXIMUM, "STOKES SHIFT" AND DEGREE OF FLUORESCENCE POLARISATION AS a FUNCTION OF PH AND TIME OF STORAGe

\begin{tabular}{|c|c|c|c|c|c|c|c|c|c|c|c|c|}
\hline \multirow[t]{2}{*}{$p H$} & \multicolumn{4}{|l|}{$o h$} & \multicolumn{4}{|l|}{$I h$} & \multicolumn{4}{|l|}{$24 h$} \\
\hline & $\begin{array}{l}A b s . \\
\max . \\
(m \mu)\end{array}$ & $\begin{array}{l}\text { Fluor. } \\
\text { max. } \\
(m \mu)\end{array}$ & $\begin{array}{l}\text { Stokes } \\
\text { shift } \\
(m \mu)\end{array}$ & $p$ & $\begin{array}{l}A b s . \\
\max . \\
(m \mu)\end{array}$ & $\begin{array}{l}\text { Fluor. } \\
\text { max. } \\
(m \mu)\end{array}$ & $\begin{array}{l}\text { Stokes } \\
\text { shift } \\
(m \mu)\end{array}$ & $p$ & $\begin{array}{l}A b s . \\
\max . \\
(m \mu)\end{array}$ & $\begin{array}{l}\text { Fluor. } \\
\text { max. } \\
(m \mu)\end{array}$ & $\begin{array}{l}\text { Stokes } \\
\text { shift } \\
(m \mu)\end{array}$ & $p$ \\
\hline 2.2 & $62 \mathrm{I}$ & 647 & 26 & $0 . \mathrm{I}_{4}$ & 621 & 646 & 25 & o. I 8 & 622 & 646 & 24 & 0.23 \\
\hline 3 & 617 & 647 & 30 & 0.08 & 617 & 646 & 29 & 0.18 & 620 & 647 & 27 & 0.23 \\
\hline 4 & 6 I 7 & $65 I$ & 34 & 0.05 & 627 & 651 & 34 & 0.06 & $6 \mathrm{I}_{7}$ & $65^{I}$ & 34 & 0.05 \\
\hline 5 & 617 & 654 & 37 & 0.02 & 617 & 651 & 34 & 0.02 & 617 & $65^{2}$ & 35 & 0.03 \\
\hline $5 \cdot 3$ & 617 & 653 & 36 & 0.01 & 617 & 653 & 36 & 0.01 & 617 & 653 & 36 & 0.03 \\
\hline 5.9 & $6 \mathrm{I} 7$ & 654 & 37 & 0.02 & 617 & 654 & 37 & 0.03 & $6 \mathrm{I}_{7}$ & 654 & 37 & 0.04 \\
\hline 6 & 617 & 654 & 37 & $0.0 I$ & 6I 7 & 654 & 37 & 0.03 & 617 & 654 & 37 & 0.04 \\
\hline 6.5 & 617 & 653 & 36 & $0.0 I$ & 617 & 654 & 37 & 0.06 & $6 \mathrm{I} 7$ & 654 & 37 & 0.07 \\
\hline 7 & 617 & 653 & 36 & 0.02 & 617 & 653 & 36 & 0.05 & 6 I 7 & 653 & 36 & 0.09 \\
\hline $7 \cdot 4$ & 617 & 653 & $3^{6}$ & 0.03 & 617 & $65^{2}$ & 35 & 0.06 & 617 & $65 I$ & 34 & o. Io \\
\hline 8 & 617 & $65 I$ & 34 & 0.07 & 616 & $65^{2}$ & 36 & 0.10 & 614 & 647 & 33 & 0.18 \\
\hline 9 & 616 & 646 & 30 & o.I3 & 615 & 645 & 30 & 0.16 & 612 & 643 & 31 & o. I6 \\
\hline
\end{tabular}


the absorption spectra in the red. However, the broadening of the absorption band at high and low $\mathrm{pH}$ was not reflected in the fluorescence band.

In Table I the location of absorption bands, the "Stokes shift" and the fluorescence polarisation is given versus $\mathrm{pH}$, at different times after preparation (stored in the dark at $20^{\circ}$ ). The table shows that the location of the fluorescence maximum of freshly prepared C-phycocyanin from Synechococcus was at about $654 \mathrm{~m} \mu$ at $\mathrm{pH} 5$ and 6 (Stokes shift $37 \mathrm{~m} \mu$ and $p=0.01$ ). At $\mathrm{pH} 9$ and 3 it was at about $646 \mathrm{~m} \mu$ (Stokes shift $30 \mathrm{~m} \mu$ and $p=0.13$ ). Fluorescence polarisation and "Stokes shift" thus appear to be correlated with $\mathrm{pH}$ in a way similar to that found for particle size.

If we assume that the high values of fluorescence polarisation and low values of Stokes shift are indicative of the smallest fragments of phycocyanin, it follows also that at $\mathrm{pH} 8$ the chromoprotein was partly broken after $2 \mathrm{~h}$ while after $24 \mathrm{~h}$ a splitting occurred at all $\mathrm{pH}$ values except 5 and 6 . After $72 \mathrm{~h}$ even at these values the chromoprotein was affected. As the preparations were not purified, it might be that certain enzymic and uncoloured cell components were responsible for acceleration, or even effectuation of the splitting phenomena.

A relation of "Stokes shift" and fluorescence depolarisation with size of pigmented unit may be of importance in a study of other fluorescing pigment systems, such as the far-red chlorophyll forms (cf. refs. 5-7).

Biophysical Research Group, Institute of Physics,

J. C. GoedheER State University Utrecht,

F. BIRNIE

Utrecht (The Netherlands)

I Th. Svedberg and I. B. Eriksson, J. Am. Chem. Soc., $5^{\text {I }}$ (1932) 3998.

2 I. B. ERIKSSON-QUenSEl, Biochem. J., 32 (1938) 585.

3 J. C. GoE:DHEER, Thesis, Utrecht, I957.

4 S. S. Brody and M. Brody, Biochim. Biophys. Acta, 50 (I96I) 348.

5 J. S. Brown and C. S. French, Biophys. J., I (I96I) 539.

6 J. C. GoedheEr, Biochim. Biophys. Acta, 88 (I964) 304.

7 S. S. Brody ANd M. Brody, Photosynthetic Mechanisms of Green Plants, Natl. Acad. Sci. Natl. Res. Council Publ., I I 45 (1963).

Received October 7 th, I964

Biochim. Biophys. Acta, 94 (1965) 579-58I

\section{Sc 43036}

\section{Protein precipitation by uncharged water-soluble polymers}

Lipids and lipoproteins are precipitated by polyelectrolytes such as dextran sulfate and heparin, which probably act as liquid ion exchangers. Several proteins are thus irreversibly precipitated. AlBERTSSON ${ }^{1}$ described a novel type of protein precipitation by uncharged water-soluble polymers. Polyethyleneglycol precipitated proteins depending on the concentration of the polymer and the type of ions present in the reaction mixture. While this manuscript was in preparation PoLson et al. ${ }^{2}$ reported on the precipitation of $\gamma$-globulin and fibrinogen by linear polymers. These findings have been confirmed and extended in the present report.

Several uncharged water-soluble polymers, such as polyethyleneglycol of mol. wt. 500, 4000, 6000, 20000 and IO $^{6}$ (ref. 3), polypropyleneglycol of mol. wt. 400-500, 